\title{
Stress Distribution in the Abutment and Retention Screw of a Single Implant Supporting a Prosthesis with Platform Switching
}

Angel Alvarez-Arenal, DDS, $\mathrm{PhD}^{1} /$ Luis Segura-Mori, $\mathrm{DDS}^{2} /$

Ignacio Gonzalez-Gonzalez, DDS, $\mathrm{PhD}^{3} /$ Angel Gago, $\mathrm{DDS}^{4}$

\begin{abstract}
Purpose: Three-dimensional finite element analysis was conducted to evaluate and compare the stress distribution in the abutment and retention screw of implant-supported single crowns with platform switching and with a conventional platform under vertical and oblique loading. Materials and Methods: Two finite element models were created simulating an osseointegrated implant ( $4 \times 10 \mathrm{~mm}$, platform $4.1 \mathrm{~mm}$ ) embedded in jawbone. One model simulated a 4-mm-diameter abutment connection (conventional model) and the other represented a 3.8-mm-diameter abutment connection (platform-switched model). A crown with a cobalt-chromium framework and feldspathic porcelain veneering was applied to the titanium abutment. Static vertical and oblique loads were applied to the crown, with a maximum load of $150 \mathrm{~N}$. Results: In both models, the highest stress values occurred in the abutment during vertical and oblique loading. Nevertheless, the von Mises stresses in the abutment and the retention screw were lower in the platform-switched model than in the conventional model. During axial loading, the abutment and screw supported slightly less stress in the conventional model than in the platform-switched model. Increases in the angle of force application caused a progressive increase in stresses in the abutment and screw in both models. The maximum stress was distributed at the margin and transgingival area of the abutment and on two-thirds of the flat area and the first threads of the retention screw in both models. Conclusions: Platform switching reduced the stress values on the abutment and retention screw of a single-unit prosthesis during oblique loading. Regardless of whether platform switching was employed, the stress on the abutment and screw gradually increased as the loading direction changed from vertical to 45 degrees oblique. The locations and distributions of stresses were similar in both models. INT J ORAL MAXILLOFAC IMPLANTS 2013;28:e112-e121. doi: 10.11607/jomi.2813
\end{abstract}

Key words: abutment, finite element analysis, platform switching, retention screw, stress

$\mathrm{T}$ reatment with dental implants to replace one or more lost teeth is a predictable and safe method, with survival rates of $89.4 \%$ for single crowns and $77.8 \%$ for fixed partial prostheses over 10 years. ${ }^{1}$ Implantsupported restorations have many advantages over

\footnotetext{
${ }^{1}$ Professor and Chairman, Department of Prosthodontics and Occlusion, School of Dentistry, University of Oviedo, Spain. ${ }^{2}$ Private Practice, Madrid, Spain.

${ }^{3}$ Associate Professor, Department of Prosthodontics and Occlusion, School of Dentistry, University of Oviedo, Spain. ${ }^{4}$ Assistant Professor, Department of Prosthodontics and Occlusion, School of Dentistry, University of Oviedo, Spain.
}

Correspondence to: Dr Angel Alvarez-Arenal, Department of Prosthodontics and Occlusion, School of Dentistry, C/Catedratico Serrano s/n, 33006 Oviedo, Spain.

Email: arenal@uniovi.es

@2013 by Quintessence Publishing Co Inc. tooth-supported fixed prostheses. A large amount of research has been carried out to determine which factors influence the preservation or loss of the bone around implants, which has helped to achieve the high rates mentioned and reduce the risk of implant failure as a result of peri-implant bone loss. The studies by Gardner ${ }^{2}$ and Lazzara and Porter ${ }^{3}$ focused interest on the platform-switching concept, which consists of the placement of abutments and prosthetic elements with a diameter smaller than that of the implant platform. In subsequent years many clinical, histomorphometric, and biomechanical studies were published to prove the efficacy of this procedure in preserving periimplant bone. All commented on the clinical result of less peri-implant bone loss in platform-switched models than in conventional models. ${ }^{4-9}$ Although no significant differences were found in the few available histomorphometric analyses, ${ }^{10,11}$ this was perhaps a result of the small size of the samples and the insufficient 
time employed. On the other hand, biomechanical studies confirm the clinical data, with results showing that the stresses in the bone around the implant neck were lower in platform-switched models than in those without platform switching ${ }^{12-14}$ and regardless of the type of implant-abutment connection, intensity, and direction of occlusal loading. ${ }^{15,16}$

However, given that the platform-switching advantage manifests itself in a reduction in bone loss and stresses in the bone around the implant, there are few studies in the literature demonstrating the influence of platform switching on the distribution of stresses on the abutment and retention screw of a single-implantsupported crown and the effects of occlusal loading on this kind of restoration. A study carried out by Maeda et $\mathrm{al}^{12}$ discussed how the stress is distributed lengthwise by the abutment up to the bone-implant contact in the direction of the applied force, a study undertaken by Hsu et al $^{14}$ showed how the platform-switching model concentrated the stress at the implant-abutment interface level, and a study by Rodríguez-Ciurana et al ${ }^{15}$ revealed that the tensions in the implant-abutment assembly were higher in assemblies with platform switching than in those without platform switching. In any case, there are insufficient and contradictory data with regard to the type of prosthetic components and the main concentration of stress in prosthetic components to provide definitive guidelines to avoid and prevent technical and mechanical risks. Mechanical and technical problems are relatively frequent in implantsupported fixed prostheses, although they are significantly more common with tooth-supported fixed prostheses. ${ }^{1}$ In a systematic review referring to an implant-supported prosthesis without platform switching, screw loss was responsible for $8.2 \%$ of failures, ${ }^{17}$ $6 \%$ of failures ${ }^{18}$ were caused by mechanical problems, and screw fracture accounted for $2 \%$ of failures. ${ }^{17,18}$

Therefore, the hypothesis is for the present study as follows: platform switching on an implant-supported single crown will decrease and improve the stress distribution in the abutment and retention screw compared to a non-platform-switched assembly. The aim of the present study was to determine the quantity and distribution of stresses on the abutment and retention screw of an implant-supported single crown with platform switching under occlusal axial and nonaxial loading and compare this to the stresses seen without platform switching.

\section{MATERIALS AND METHODS}

\section{Finite Element Model Design}

A three-dimensional (3D) finite element model was constructed to evaluate the stress distribution in the abutment and retention screw of an implant-supported single crown. An edentulous mandibular posterior bone segment (type 2, according to the classification by Lekholm and Zarb ${ }^{19}$ ) was modeled; the bone was assumed to be $23 \mathrm{~mm}$ in height inferosuperiorly and $12 \mathrm{~mm}$ in width buccolingually formed by cortical bone and trabecular bone, as other authors noted in their studies. $^{20-22}$

The geometry of the Certain Prevail Implant (Biomet 3i) $(4.0-\mathrm{mm}$ body diameter, $4.1-\mathrm{mm}$-diameter platform, $13 \mathrm{~mm}$ length) was used as a reference to model a threaded implant. One finite element model included a 4.1-mm-diameter, 5-mm-high abutment connection and gold retention screw (Gold-Tite, Biomet 3i) to serve as the non-platform-switched model. The other implant/abutment model simulated a 3.8- $\mathrm{mm}$ diameter, 5-mm-high abutment connection (Gingi Hue, Biomet 3i) with a gold retention screw to serve as the platform-switched model. A cobalt-chromium (Co$\mathrm{Cr}$ ) alloy and porcelain-fused-to-metal crown, $8 \mathrm{~mm}$ in height, $10.6 \mathrm{~mm}$ in buccolingual and mesiodistal diameter, and with $3 \mathrm{~mm}$ of occlusal thickness $(1 \mathrm{~mm}$ of alloy; the veneering material varied from $1 \mathrm{~mm}$ to $1.5 \mathrm{~mm}$ from cervical to occlusal area), was applied to the titanium abutment.

\section{Material Properties and Interface Conditions}

All the materials used in these models were considered linearly elastic, homogeneous, and isotropic. Values for elastic moduli and Poisson ratios of the different materials were taken from the literature ${ }^{23-26}$ (Table 1).

It should be noted that a system made up of one or more elements is homogeneous only when its properties are identical in all its parts. In addition, if the directional properties (such as thermal dilatation, mechanical resistance, or the speed of light) are the same in all directions, it is considered to be isotropic. On the other hand, static linear models have been used in studies with finite elements and are considered reliable if the structure shows a linear relationship between tension and deformity until a level of stress known as the proportional limit is reached and if all volumes are combined to form a single unit. Bone is not isotropic or linearly elastic. ${ }^{25}$ However, it was considered to be so for the present study, because it is necessary to perform certain simplifications to make it possible to process and obtain results ${ }^{12-16,27}$ at a reasonable computational cost.

Furthermore, the bone-implant interface was considered perfect, with $100 \%$ osseointegration, in agreement with similar studies. ${ }^{22,28}$ The cement layer between the crown and the abutment was not considered, and the crown-abutment and the abutment-implant were assumed to be completely bonded without any loosening. 
Table 1 Mechanical Properties of Modeled Materials and Structures

\begin{tabular}{llccl} 
Material & Structure & Young's modulus (GPa) & Poisson ratio & \multicolumn{1}{c}{ Reference } \\
\hline Titanium & Implant & 110.0 & 0.35 & ${\text { Lewinstein et } \mathrm{al}^{23}}^{23}$ \\
\hline Titanium alloy & Abutment & 107.2 & 0.33 & Suansuwan and Swain $^{24}$ \\
Gold alloy type III & Retention screw & 100.0 & 0.30 & Geng et al $^{25}$ \\
Co-Cr alloy & Crown framework & 218 & 0.33 & Anusavice and Coscone $^{26}$ \\
\hline Feldspathic porcelain & Crown veneer & 68.9 & 0.28 & Geng et al $^{25}$ \\
\hline
\end{tabular}

\section{Loading and Boundary Conditions}

For both models (with and without platform switching), a load of $150 \mathrm{~N}$ was applied to the central occlusal fossa of the crown and systematic varied loading directions were simulated, with buccolingual loading at angles of $0,15,30$, and 45 degrees in relation to the long axis of the implant. These angles were chosen because they make it possible to simulate the biomechanical performance of angled implants, since these are frequently encountered clinically.

The data for von Mises stresses and strain were produced numerically, and stresses in the finite element models were color-coded to allow comparison of the biomechanical differences between the conventional and platform-switched models. The finite element models representing mandibular bone segments and the implant assemblies were created and meshed using commercial 3D finite element software (ANSYS 11.0, ANSYS) and processed in a computer (HewlettPackard xw8400, microprocessor Intel Xeon Dual Core $5100,2.6 \mathrm{GHz}, 16 \mathrm{~GB}$ of RAM, dual hard drives of $250 \mathrm{~GB}$ SATA and 2.5 TB $[7,200 \mathrm{rpm}])$. The model that simulated a conventional restoration was composed of 59,206 elements and 73,237 nodes, and the platform-switched model was composed of 61,673 elements and 77,091 nodes. The bone, dental implant, abutment, veneering framework, veneer material, and retention screw were modeled by means of SOLID187, a higher-order 3D, 10-node element with three degrees of freedom at each node and translations in the nodal $x-, y-$, and $z$-axes. The element in question has quadratic behavior in its displacements and is well suited for the modeling of irregular meshes.

\section{RESULTS}

The study focused on the distribution and values of the highest stress/deformation; thus, the von Mises stress was chosen to display the results of the computations.

\section{Stress/Deformation Distribution in the Abutment}

The stresses/deformations in each model under varied loading directions were examined carefully. The abutment in the platform-switched model (Table 2) displayed stresses of $39.594 \mathrm{MPa}$ with an axial load of $150 \mathrm{~N}$; these stresses increased progressively as the load became more inclined. When the force direction was inclined by 15 degrees, the stress was approximately four times greater $(155.61 \mathrm{MPa})$, at 30 degrees it was seven times greater (270.06 MPa), and at 45 degrees it was nine times greater (371.48 $\mathrm{MPa})$.

The von Mises stresses in the abutment of the platform-switched model were lower than those seen in the abutment of the conventional model for all loading directions except for axial loading (36.028 MPa), which was slightly higher in the platform-switched model. The reduction of stresses in the abutment with platform switching, versus the conventional abutment, was $36.91 \%$ at 15 degrees, $39.69 \%$ at 30 degrees, and $40.07 \%$ at 45 degrees, but under axial loading the stresses increased by $9.9 \%$. The greatest stress was registered in the abutment in the conventional model for any off-axis load. However, the stress gradually increased from 0 to 45 degrees in both models. In contrast, the greatest deformation of the abutment occurred in the platform-switched model with the most inclined load (45 degrees), and for both models, the deformation of the abutment increased gradually as the inclination of the load increased, although the increase was slightly smaller in the conventional model.

For both models, during axial loading, the von Mises stresses decreased at the margin of the abutment and gingiva; this also occurred in the most coronal and medial zones of the abutment. Under oblique loading $(15,30$, or 45 degrees) and regardless of the model, the stress disappeared in the most coronal zone of the abutment and was concentrated in a well-delineated zone that did not extend far from the margin and the gingival part of the abutments (Figs 1 and 2). 
Fig 1 Von Mises stress distribution in the abutment under vertical and oblique loading in the platform-switched model; (a) 0 degrees, (b) 15 degrees, (c) 30 degrees, (d) 45 degrees.
Fig 2 Von Mises stress distribution in the abutment under vertical and oblique loading in the conventional model; (a) 0 degrees, (b) 15 degrees, (c) 30 degrees, (d) 45 degrees.

\section{Stress/Deformation Distribution in the Retention Screw}

In comparison to the conventional model, the platform-switched model showed lower levels of von Mises stress under oblique loading $(15,30$, and 45 degrees); the reductions were $34.39 \%$ at 15 degrees,
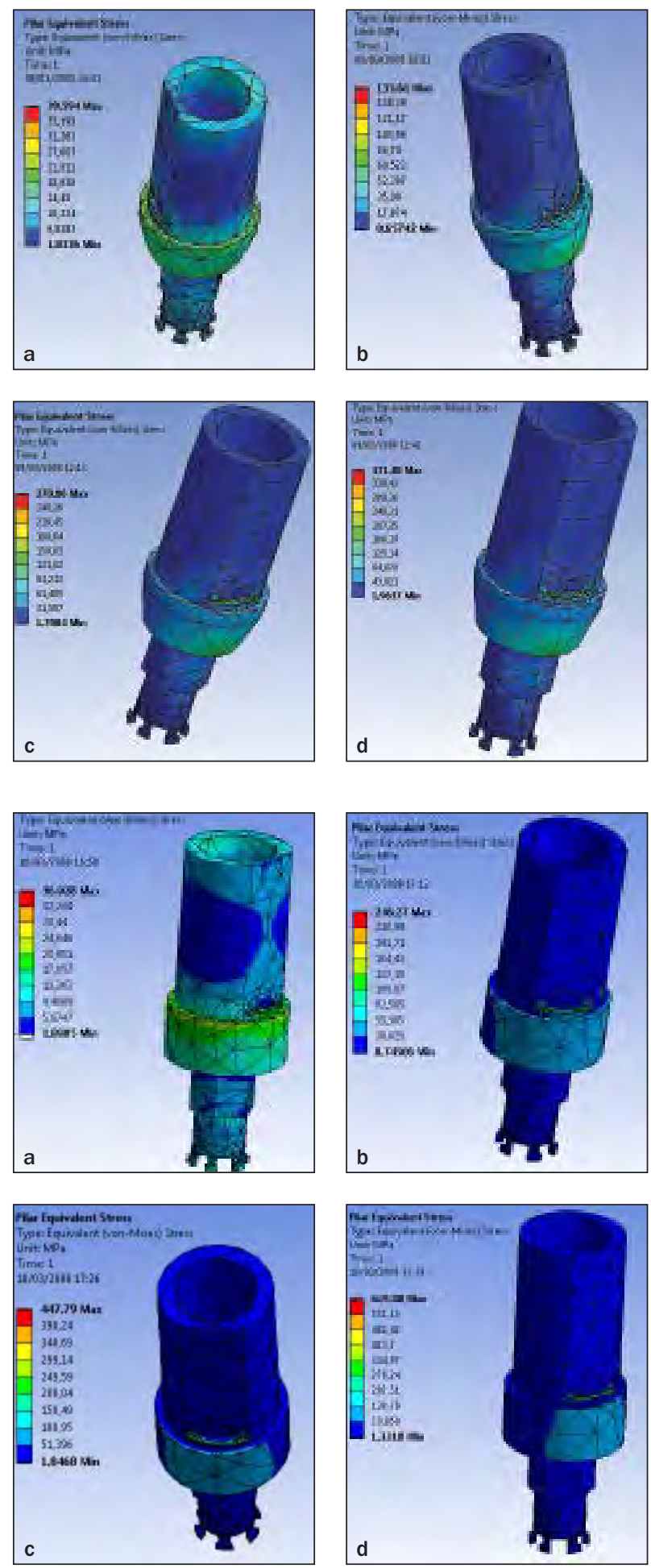

$33.31 \%$ at 30 degrees, and $37.73 \%$ at 45 degrees of inclination. However, axial loading increased the stress in the screw of the platform-switched model by $22.89 \%$ (20.509 MPa, versus $16.689 \mathrm{MPa}$ in the conventional model). Nonetheless, the stress gradually increased in both models as loading changed from a vertical to a 
Table 2 Von Mises Stresses and Deformation in the Abutment, Retention Screw, and Implant in Platform-Switched and Conventional Models During 150-N Load Application

\begin{tabular}{|c|c|c|c|c|c|c|c|c|}
\hline \multirow[b]{2}{*}{ Component/model } & \multicolumn{4}{|c|}{ Von Mises stresses (MPa) } & \multicolumn{4}{|c|}{ Deformation (mm) } \\
\hline & $0 \mathrm{deg}$ & $15 \mathrm{deg}$ & $30 \mathrm{deg}$ & $45 \mathrm{deg}$ & $0 \mathrm{deg}$ & $15 \mathrm{deg}$ & $30 \mathrm{deg}$ & $45 \mathrm{deg}$ \\
\hline \multicolumn{9}{|l|}{ Abutment } \\
\hline Platform-switched & 39.594 & 155.612 & 270.063 & 371.484 & 0.0063 & 0.0172 & 0.0296 & 0.0406 \\
\hline Conventional & 36.028 & 246.273 & 447.792 & 619.883 & 0.059 & 0.0162 & 0.0279 & 0.0381 \\
\hline \multicolumn{9}{|l|}{ Retention screw } \\
\hline Platform-switched & 20.509 & 55.703 & 99.475 & 136.623 & 0.0053 & 0.0096 & 0.0152 & 0.0202 \\
\hline Conventional & 16.689 & 84.906 & 149.163 & 203.052 & 0.0052 & 0.0095 & 0.0152 & 0.0201 \\
\hline \multicolumn{9}{|l|}{ Implant } \\
\hline Platform-switched & 38.623 & 48.867 & 77.737 & 103.690 & 0.0053 & 0.0084 & 0.0119 & 0.0152 \\
\hline Conventional & 37.355 & 53.039 & 85.521 & 112.352 & 0.0053 & 0.0087 & 0.0125 & 0.0157 \\
\hline
\end{tabular}

45-degree oblique load, with greater increases in the conventional model (Table 2). With respect to deformation of the retention screw, there was no difference between the conventional and the platform-switched models. Although deformation of the retention screw gradually increased with the inclination of the applied force, it was always less than the deformation found in the abutment.

Under vertical loading, the stress distribution was similar in both models. The von Mises stresses were seen adjacent to the apical half of the flat area and the first two to three threads of the screw, as well as on the apical part of the screw-head at the abutmentretention screw interface. When oblique loads (from 15 to 45 degrees) were applied, the concentration of stress remained similar in the two models, although there were differences versus vertical loading. The stresses were distributed on the apical half of the flat part of the screw and the first thread, and on a small surface of the most apical area of the screw (Figs 3 and 4).

\section{DISCUSSION}

\section{Limitations of Justifications for the Finite Element Model}

This study applied 3D finite element analysis to evaluate the effect of platform switching on stress distribution in the abutment and retention screw during occlusal loading at different angles. Finite element analysis has been used for more than 20 years to provide information about the mechanical environment in the implant, peri-implant bone, prosthetic components, and prostheses in many different situations. However, the use of mathematical models and computer simulations involves undertaking several simplifications related to material properties, geom- etry, and loading conditions, meaning that the data do not directly correspond to the results in clinical practice. Thus, when applying the results of finite element analyses, a qualitative comparison between models is recommended, rather than a focus on quantitative data. ${ }^{29}$ Therefore, the present models cannot provide absolute, realistic values of stress/strain on the abutment and retention screw in a clinical situation. However, for a comparative study, such simplifications are considered to be reasonable insofar as the constructed models reflect the clinical situation. Material properties greatly influence the distribution of stress and deformation in a structure, and although these properties can be modeled as isotropic, transversely isotropic, or anisotropic, in most studies (including the present study), the assumption is made that the materials are homogeneous and linearly isotropic. ${ }^{16,20,30,31}$

The Gingi Hue cementable abutment has been used by other authors in studies of the platform-switched model, ${ }^{16}$ whereas other studies that modeled prosthetic components used a straight abutment similar to those used in the present study. ${ }^{13,15,20,30}$ Loads are applied to a healing abutment ${ }^{12,22,32}$ or directly to the implant. ${ }^{33,34}$ Although modeling of the retention screw is not common in the literature, the Gold-Tite retention screw used here is different from that employed by Assunçao et al. ${ }^{20}$

A superstructure crown of $\mathrm{Co}-\mathrm{Cr}$ and feldspathic porcelain veneering material was also modeled, as has been done in other studies. $16,20,30,35$ However, in the present work, the data from the crown and veneering material were not included, so that the present efforts could be focused exclusively on the abutment and retention screw. This fact will not influence the distribution of the stress on the abutment and screw because these variables remained constant for both models in all applied loading directions. 
Fig 3 Von Mises stress distribution in the retention screw under vertical and oblique loading in the platform-switched model; (a) 0 degrees, (b) 15 degrees, (c) 30 degrees, (d) 45 degrees.
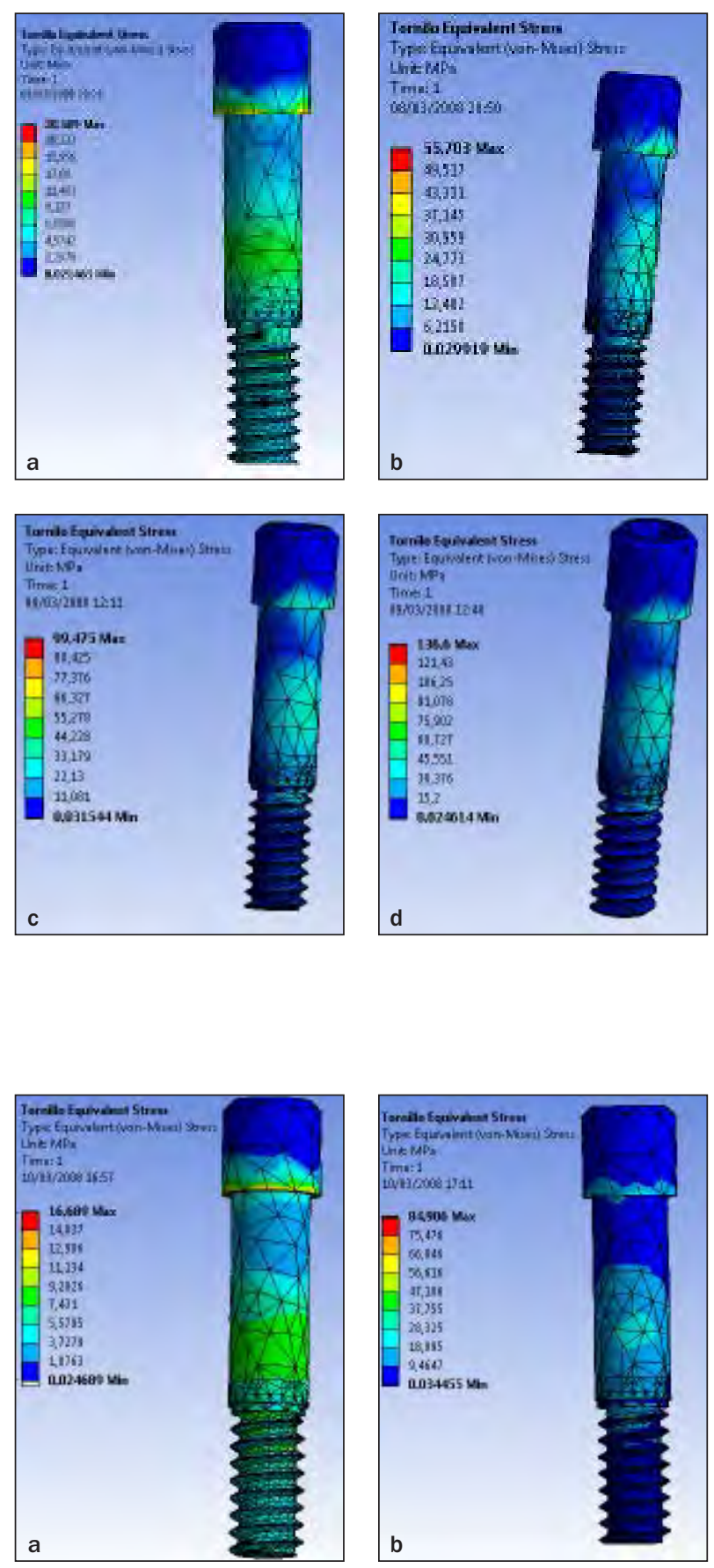

Fig 4 Von Mises stress distribution in the retention screw under vertical and oblique loading in the conventional model; (a) 0 degrees, (b) 15 degrees, (c) 30 degrees, (d) 45 degrees.
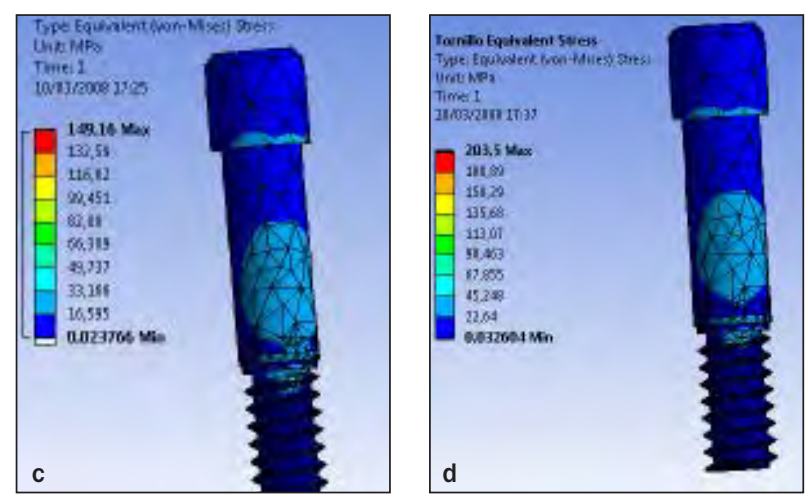

The International Journal of Oral \& Maxillofacial Implants e117 
When applying finite element analysis to an implant/prosthesis system, it is important to consider not only axial loading but also oblique occlusal forces. In this study, a 150-N load was applied vertically and 15, 30 , and 45 degrees off-axis with respect to the occlusal surface of the crown. Although bite force studies indicate considerable variation from one area of the mouth to another and between individuals, $150 \mathrm{~N}$ is close to the average recorded in patients with dental implants, ${ }^{36,37}$ it is cited in other studies, ${ }^{21,38}$ and it is considered a normal occlusal force that is very close to actual masticatory forces. ${ }^{39}$ Nevertheless, mastication produces complex patterns of force that are impossible to reproduce, and although the results of a finite element analysis that applies isolated forces reflect reality very closely, ${ }^{40,41}$ the clinician must consider this limitation when discussing the clinical implications of a finite element analysis. Nevertheless, some studies have applied horizontal loads of 10 to $40 \mathrm{~N},{ }^{12,16,30}$ together with axial loading, while other studies have used loads varying from $100 \mathrm{~N}^{13,22,32,34,42}$ up to $250 \mathrm{~N} .{ }^{13}$ The different inclinations of $0,15,30$, and 45 degrees the applied loads were chosen because they permit examination of the biomechanical performance of inclined implants and represent a variety of actual clinical situations. Other authors have examined only one inclination $\left(0\right.$ degrees $\left.^{12}\right)$ or two inclinations $(0$ and 15 degrees, ${ }^{22} 10$ and 30 degrees, $^{34}$ or 0 and 45 degrees $^{14}$ ), which reduces the number of studied situations in comparison with the present study. Other studies have applied loads of 0 and 90 degrees, ${ }^{13,16,43}$ which may not be realistic because horizontal loads are rarely (if ever) produced during normal chewing or parafunctional habits. Regarding this, Chun et al ${ }^{32}$ applied loads with directions similar to the present study $(0,15,30$, and 60 degrees).

In addition, the design of the occlusal surface may influence the stress distribution, and whenever possible a cusp-to-fossa relationship in maximum intercuspation with no eccentric or interceptive occlusal contacts in the crown should be used, given that maximum stresses were concentrated on the porcelain surface at the loading points. ${ }^{20,44}$ In the current study, the location of force application was specifically described as the cusp's central fossa on the occlusal surface of the crown. The cusp-fossa contact area was a small surface and not a point, as described in other studies. ${ }^{12-14,22,28}$ In any case, the application of occlusal force at a point or on a surface can be considered equivalent according to the Saint-Venant principle. Furthermore, the force vectors simulating the actions of the muscles of mastication, the temporomandibular joints, and the cement layer were not modeled, and this should be considered an inherent limitation of this study.

\section{Clinical and Biologic Implications}

The present study indicated that the stresses on the abutment in models with and without platform switching gradually increase as the load inclination increases with respect to the long axis of the implant. This trend is similar to what may be found in the existing literature concerning the implant neck and the peri-implant bone. ${ }^{33,45}$ In addition, it was seen that an increased loading angle significantly worsened the distribution of stress and strain. An oblique loading angle is, therefore, believed to be the most severe loading condition and should be avoided wherever possible. ${ }^{33}$ However, the stresses were lower in the platform-switched model than in the conventional model under oblique loading and slightly higher during axial loading. This abutment performance under loads with different inclinations is in keeping with what has been discussed in previous studies, in which the stresses suffered by the abutment with and without platform switching under axial loading ${ }^{12-14}$ and under various conditions of oblique loading were analyzed. ${ }^{15} \mathrm{~A}$ possible reason for the lower stresses in the abutment of the conventional model may be the greater diameter of the abutment, which distribute the loads better as the result of increased contact area between the abutment, crown, and implant. This is similar to what occurs with wide implants, which lower the values of stress in the bone and implant in relation to narrower implants. ${ }^{33,46} \mathrm{An}$ other possible reason may be the fact that the two structures (crown and abutment) have different elastic moduli. However, similar to what occurred with the present abutment, in models of fixed partial prostheses supported by straight and angled implants, Cruz et al ${ }^{30}$ noted that the greatest stresses occurred during vertical loading in the mesial and distal neck area of both straight and angled implants. Similar results can be found in the design of tooth/implant-supported fixed dental prostheses with rigid and nonrigid connectors. ${ }^{31}$

Of the structures involved in the present studyabutment, screw, implant, cortical and trabecular bone (no data available for the latter two) - the abutment is the structure that supported the most stress, especially under an oblique load, regardless of the platform. This result coincides with other studies ${ }^{15,47,48}$ that reported increased stress in the abutment and implant-abutment interface in a platform-switched configuration; in contrast, Pellizzer et al ${ }^{48}$ found a similar distribution pattern but only a minor area of stress concentration in the abutment and the implant/abutment interface. Therefore, the prosthetic abutment can be an important factor in the transmission and distribution of the stress to the implant and peri-implant bone. In the present analysis, platform switching did not dramatically modify the location and distribution of the stress in the abutment; in both models, the highest stresses were seen at the 
margin and the transgingival area of the abutment. This fact supports the need to increase the resistance of the gingival area of the abutments. However, Sun et $\mathrm{al}^{49}$ in a conventional model made up of an implant and solid abutment simplified into one unit, and an all-ceramic superstructure, reported that the greatest displacement of the implant-abutment complex was at the top of the abutment under both axial and oblique loads, and the displacement decreased from the top of the abutment to the bottom of the implant. Nevertheless, deformation of the abutment, although it was more pronounced in the model without platform switching during any angulation of force application, was still below the elastic limit or abutment fracture limit reported by Aramouni et $\mathrm{al}^{50}$; that is to say, the abutment would support the stresses without a problem, regardless of the inclination of the load, and this low fracture rate is supported by the literature. ${ }^{17}$

In the present study, the stress in the retention screw of the abutment showed a similar performance to that of the abutment. The stress in the screw of the platformswitching model at any degree of load inclination was lower than in the conventional model, and in both models, the stress in the screw gradually increased as the load became more inclined. However, as had occurred in the abutment under an axial load, the retention screw of the conventional model supported less stress than that of the platform-switched model. Therefore, the absence of platform switching, with an exception in the case of axial loads, may lead to overloading and instability of the retention screw, resulting in fracture or loss of the screw. These phenomena are the result of the larger diameter of the abutment of the conventional model, versus the platform-switched abutment, which results in a higher torque in the conventional abutment model than in the platform-switched model. Therefore loss and fracture are more likely to occur in the conventional model. In addition, this major stress could be transferred from the retention screw to the implant, compromising osseointegration. However, this is a controversial claim, because in the present study, the stress value in the screw was higher than that in the implant for any load angulation. This result is in disagreement with the results of a study, ${ }^{51}$ very similar to the present study, that reported a large amount of stress around the implant neck and little stress concentrated along the abutment screw. According to this trend, the stress value will increase in the screw of a single implant-supported prosthesis in the absence of a precise fit of the framework to the implant. ${ }^{20}$

On the other hand, in this study, platform switching did not have a significant influence on the location and distribution of the stress/deformation in the retention screw. In both models it was distributed along the apical half of the screw stem, dissipating toward the first and second threads (and to a lesser degree along the apical area of its head), that is, in the area of transition between the flat and the threaded part of the screw, and not along the screw itself. ${ }^{51}$ This result shows the possible location of frequent screw fractures and is in agreement with what has been empirically observed in clinical practice and with the manufacturers of the Brånemark System, who have admitted that the retention screw is the weakest part of the system. It may then be of interest to reduce the stress on the screw with platform switching or by using rigid materials for the manufacture of the prosthetic crown, because it has been proven that materials with a high modulus of elasticity decreased the stress within retention screws and frameworks, ${ }^{20,52,53}$ as did the use of an internalconnection implant system. Despite the fact that there are many different joints between abutments and implants, an internal connection (in which part of the abutment is introduced into the implant structure) can reduce biomechanical complications in the abutment screw. ${ }^{51,54}$ A study ${ }^{55}$ that compared, in vitro, four connections of four different systems showed that the biomechanical fatigue and the elastic or fracture limit of the components were directly dependent on the type of implant-abutment connection. In the case of overloading, a fracture would occur in the weakest area of the implant-abutment-screw complex.

In the present study, the deformation seen in the abutment screw was not affected by a narrower platform. However, it was affected by load inclination. For both models, the deformation was similar during axial loading. However, when a load was applied at 45 degrees, the deformation was four times higher than during vertical loading. These deformation values in the screw were, however, lower than those registered in the abutment and may be below the values for screw fracture or even below the force required for loosening. Therefore, loosening of the screw should be considered as a consequence of stress/deformation and should be seen as a possible sign of overload preceding a fracture of the screw. ${ }^{56-58}$

\section{CONCLUSIONS}

The present research was performed in accordance with accepted finite element analysis methodology. A unique convergent finite element model was employed for each of the abutment designs; therefore, no statistical sampling was performed. Within the limitations of this study, the following conclusions can be drawn:

1. The von Mises stresses on the abutment and abutment screw were lower in the platform-switched model than in the conventional model during oblique loading. 
2. The lowest stress values on the abutment and screw occurred during axial loading and were slightly lower in the conventional model than in the platform-switched model.

3. The stresses on the abutment and retention screw gradually increased as the load became more inclined in both the platform-switched and the conventional models.

4. Concentration of stresses occurred in the transgingival area and at the margin of the abutment, in two-thirds of the flat stem of the retention screw, and in the flat area and the first threads of the retention screw. Platform switching had very little influence on the location of stresses in the abutment and abutment screw. This was similar in both models during axial and oblique loading. Finally, it should be noted that, even though the von Mises stresses on the abutment were lower in the platform-switched model than in the conventional model, the stresses seemed to be dissipated in the form of abutment deformation, which was greater in the platform-switched model. Because of the uniqueness of each model, the finite element solutions cannot be analyzed statistically.

\section{ACKNOWLEDGMENTS}

The authors wish to thank Dr Eng Fernando Sanchez-Lasheras, who provided the computer-aided design data of the geometry of the implant, abutment, retention screw, and crown. The authors reported no conflicts of interest related to this study.

\section{REFERENCES}

1. Pjetursson BE, Brägger U, Lang NP, Zwahlen M. Comparison of survival and complications rates of tooth-supported fixed dental prostheses (FDPs) and implant-supported FDPs and single crowns (SCs). Clin Oral Implants Res 2007;18:97-113.

2. Gardner DM. Platform switching as a means to achieving implant esthetics. N Y State Dent J 2005;71:34-37.

3. Lazzara RJ, Porter SS. Platform switching: A new concept in implant dentistry for controlling post-restorative bone levels. Int J Periodont Restorative Dent 2006;26:8-17.

4. Hürzeler M, Fickl S, Zuhr O, Wachtel HC. Peri-implant bone level around implants with platform-switched abutments: Preliminary data from a prospective study. J Oral Maxillofac Surg 2008;6: 2195-2196.

5. Cappiello M, Luongo R, Di lorio D, Bugea C, Cocchetto R, Celletti R. Evaluation of peri-implant bone loss around platform-switched implants. Int J Periodontics Restorative Dent 2008;28:347-355.

6. Trammell K, Geurs NC, O'Neal SJ, et al. A prospective, randomized, controlled comparison of platform-switched and matchedabutment implants in short-span partial denture situations. Int J Periodontics Restorative Dent 2009;29:599-605.

7. Wagenberg B, Froum SJ. Prospective study of 94 platform-switched implants observed from 1992 to 2006. Int J Periodontics Restorative Dent 2010;30:8-18.

8. Cocchetto R, Traini T, Caddeo F, Celletti R. Evaluation of hard tissue response around wider platform-switched implants. Int J Periodontics Restorative Dent 2010;30:163-171.
9. Canullo L, Fedele GR, lannello G, Jepsen S. Platform switching and marginal bone-level alterations: The results of a randomized-controlled trial. Clin Oral Implants Res 2010;21:115-121.

10. Becker J, Ferrari D, Herten M, Kirtch A, Schaer A, Schwarz F. Influence of platform switching on crestal bone changes at nonsubmerged titanium implants: A histomorphometrical study in dogs. J Clin Periodontol 2007;34:1089-1096.

11. Becker J, Ferrari D, Mihatovic I, Sahm N, Schaer A, Schwarz F. Stability of crestal bone level at platform-switched non-submerged titanium implants: A histomorphometrical study in dogs. J Clin Periodontol 2009;36:532-539.

12. Maeda Y, Miura J, Taki I, Sogo M. Biomechanical analysis on platform switching: Is there any biomechanical rationale? Clin Oral Implants Res 2007;18:581-584.

13. Baggi L, Cappelloni I, Di Girolamo M, Maceri F, Vairo G. The influence of implant diameter and length on stress distribution of osseointegrated implants related to crestal bone geometry: A three-dimensional finite element analysis. J Prosthet Dent 2008;100:422-431.

14. Hsu ML, Chen FC, Kao HC, Cheng CK. Influence of off-axis loading of an anterior maxillary implant: A 3-D finite element analysis. Int J Oral Maxillofac Implants 2007;22:301-309.

15. Rodríguez-Ciurana X, Vela-Nebot X, Segalà-Torres M, RodadoAlonso C, Méndez-Blanco V, Mata-Bugueroles M. Biomechanica repercussions of bone resorption related to biologic width: A finite element analysis of three implant-abutment configurations. Int J Periodontics Restorative Dent 2009;29:479-487.

16. Chang CL, Chen CS, Hsu ML. Biomechanical effect of platform switching in implant dentistry: A three-dimensional finite element analysis. Int J Oral Maxillofac Implants 2010;25:295-304.

17. Aglietta M, Siciliano VI, Zwahlen M, et al. A systematic review of the survival and complication rates of implant supported fixed dental prostheses with cantilever extensions after an observation period of at least 5 years. Clin Oral Implants Res 2009;20:441-451.

18. Goodacre CJ, Bernal G, Rungcharassaeng K, Kan JYK. Clinical complications with implants and implant prostheses. J Prosthet Dent 2003;90:121-132.

19. Lekholm U, Zarb GA. Patient selection and preparation. In: Bränemark P-I, Zarb GA, Albreksson (eds). Tissue-Integrated Prostheses. Osseointegration in Clinical Dentistry. Chicago: Quintessence, 1985:199-209.

20. Assunçao WG, Alves Gomes E, Barao VAR, Delben JA, Tabata LF, Capello de Sousa EA. Effect of superstructure materials and misfit on stress distribution in a single implant-supported prostheses: A finite element analysis. J Craniofac Surg 2010;21:689-695.

21. Natali A, Pavan PG, Ruggero AL. Evaluation of stress induced in peri-implant bone tissue by misfit in multi-implant prosthesis. Dent Mater 2006;22:388-395.

22. Sahin S, Sehreli MC, Yalcin E. The influence of functional forces on the biomechanics of implant supported prostheses-A review. J Dent 2002;30:171-282.

23. Lewinstein I, Banks-Sills L, Eliasi R. Finite analysis of a new system (IL) for supporting an implant-retained cantilever prostheses. Int J Oral Maxillofac Implants 1995;10:355-366.

24. Suansuwan N, Swain MV. Determination of elastic properties of metal alloys and dental porcelains. J Oral Rehabil 2001;28:133-139.

25. Geng JP, Tan KBC, Liu GR. Application of finite element analysis in implant dentistry: A review of literature. J Prosthet Dent 2001;85: 585-607.

26. Anusavice KJ, Coscone P. Dental casting and soldering alloys. In Anusavice KJ (ed). Phillips' Science of Dental Materials, ed 11. St Louis: Elsevier, 2003:563-620.

27. Schrotenboer J, Tsao YP, Kinariwala V, Wang HL. Effect of microthreads and platform switching on crestal bone stress levels: A finite element analysis. J Periodontol 2008;79:2166-2172.

28. Petrie CS, Williams JH. Probabilistic analysis of peri-implant strain predictions as influence by uncertainties in bone properties and oclusal forces. Clin Oral Implants Res 2007;18:611-619.

29. Misch CM, Ismail YH. Finite element stress analysis of tooth-toimplant fixed partial denture designs. J Prosthodont 1993;2:83-92.

30. Cruz M, Wassall T, Toledo EM, da Silva Barra L, Cruz S. Finite element stress analysis of dental prostheses supported by straight and angled implants. Int J Oral Maxillofac Implants 2009;24:391-403. 
31. Özcelik FB, Ersoy E, Yilmaz B. Biomechanical evaluation of toothand implant-supported fixed dental prostheses with various nonrigid connector positions: A finite element analysis. J Prosthodont 2011;20:16-28.

32. Chun HJ, Shin HS, Han CH, Lee SH. Influence of implant abutment type on stress distribution in bone under various loading conditions using finite element analysis. Int J Oral Maxillofac Implants 2006;21: 195-202.

33. Quian L, Todo M, Matsushita Y, Koyano K. Effects of implant diameter, insertion depth, and loading angle on stress/strain fields in implant/jawbone systems: Finite element analysis. Int J Oral Maxillofac Implants 2009;24:877-866.

34. Natali AN, Pavan PG, Ruggero AL. Analysis of bone-implant interaction phenomena by using a numerical approach. Clin Oral Implants Res 2006;17:67-74.

35. Cibirka RM, Razzoog ME, Lang BR, Stohler CS. Determining the force absorption quotient for restorative materials used in the implant occlusal surfaces. J Prosthet Dent 1992;67:361-364.

36. Morneburg TR, Proeschel PA. Measurement of masticatory forces and implant loads: A methodologic clinical study. Int J Prosthodont 2002;15:20-27.

37. Morneburg TR, Proeschel PA. In vivo forces on implants influenced by occlusal scheme and food consistency. Int J Prosthodont 2003;16:481-486.

38. Soares PV, Santos-Filho PCF, Comide HA, Araujo CA, Martins LRM, Soares CJ. Influence of restorative technique on the biomechanical behaviour of endodontically treated maxillary premolars: Part II: Strain measurement and stress distribution. J Prosthet Dent 2008; 99:114-122.

39. Proeschel PA, Morneburg T. Task-dependence of activity/bite force relations and its impact on estimation of chewing force from EMG. J Dent Res 2002;81:464-468.

40. Koolstra JH, van Eijden TM. Application and validation of a threedimensional mathematical model of the human masticatory system in vivo. J Biomech 1992;25:175-187.

41. Balamonte T, Abbate MF, Pizzarello F, Lozada J, James R. The experimental verification of the efficacy of finite element modeling to dental implant systems. J Oral Implantol 1996;22:104-110.

42. Tabata LF, Assunção WG, Barão VAB, de Sousa EA, Gomes EA, Delben JA. Implant platform switching: Biomechanical approach using two-dimensional finite element analysis. J Craniofac Surg 2010;21:182-187.

43. Rodríguez-Ciurana X, Vela-Nebot X, Segalà-Torres $M$, et al. The effect of interimplant distance on the height of the interimplant bone crest when using platform-switched implants. Int J Periodontics Restorative Dent 2009;29:141-151.
44. Sevimay M, Usumez A, Eskitascioglu G. The influence of various occlusal materials on stresses transferred to implant-supported prostheses and supporting bone: A three-dimensional finite-element study. J Biomed Mater Res B Appl Biomater 2005;73:140-147.

45. Watanabe F, Hata Y, Komatsu S, Ramos TC, Fukudfa H. Finite element analysis of the influence of implant inclination, loading position, and load direction on stress distribution. Odontology 2003;91:31-36.

46. Cynthia SP, John LW. Comparative evaluation of implant designs: influence of diameter, length, and taper on strains in the alveolar crest: A three-dimensional finite element analysis. Clin Oral Implants Res 2005;16:486-494.

47. Cimen $\mathrm{H}$, Yengin E. Analyzing the effects of the platform switching procedure on stresses in the bone and implant abutment complex by FEM analysis. J Oral Implantol 2012;38:21-26.

48. Pellizzer E, Verri F, Falcón-Antenucci RM, et al. Stress analysis in platform switching implants. A three-dimensional finite element study. J Oral Implantol 2012 Oct;38:587-594. Epub 2010 Oct 8.

49. Sun YS, Long L, HU K, et al. Selection of the implant transgingival height for optimal biomechanical properties: A three-dimensional finite element analysis. Br J Oral Maxillofac Surg 2009;47:393-398.

50. Aramouni P, Zebouni E, Tashkandi E, Dib S, Salameh Z, Almas K. Fracture resistance and failure location of zirconium and metallic implant abutments. J Contemp Dent Pract 2008;9:41-48.

51. Segundo RMH, Oshima HMS, Lima da Silva IN, et al. Stress distribution of a internal connection implant prostheses set: A 3D finite element analysis. Stomatologija 2009;11:55-59.

52. Sertgoz A. Finite element analysis study of the effect of superstruc ture material on stress distribution in an implant-supported fixed prostheses. Int J Prosthodont 1997;10:19-27.

53. Çiftçi Y, Canay S. Stress distribution on the metal framework of the implant-supported fixed prostheses using different veneering materials. Int J Prosthodont 2001;14:406-411.

54. Binon PP. Implants and components: Entering the new millennium Int J Oral Maxillofac Implants 2000;15:76-94.

55. Quek HC, Tan KB, Nicholls Jl. Load fatigue performance of four implant-abutment interface designs: Effect of torque level and implant system. Int J Oral Maxillofac Implants 2008;23:253-262.

56. Balshi TJ. An analysis and management of fractured implants: A clinical report. Int J Oral Maxillofac Implants 1996;11:660-666.

57. Eckert SE, Meraw SJ, Cal E, Ow RK. Analysis of incidence and associated factors with fractured implants: A retrospective study. Int J Oral Maxillofac Implants 2000;15:662-667.

58. Schwarz MS. Mechanical complications of dental implants. Clin Oral Implants Res 2000;11:156-158. 